\title{
Educação do Campo no Plano Nacional de Educação: tensões entre a garantia e a negação do direito à educação
}

Marilene Santos ${ }^{a}$

\section{Resumo}

O artigo, de cunho bibliográfico, discute o direito à educação para as populações do campo e analisa a garantia desse direito nos documentos que balizam a política educacional no país nas últimas décadas. O material empírico analisado é composto pelo Plano Decenal de Educação (1993) e os Planos Nacionais de Educação (2001 e 2014). A análise concentra-se em refletir sobre o modo de comparecimento do debate da educação do campo nos documentos analisados, explicitando as tensões que emergem do plano vigente, que oscila entre a garantia e a não efetivação do direito à educação. Além disso, problematiza a concepção de Educação Rural e assume a perspectiva da Educação do Campo na reflexão dos textos legais. As conclusões assinalam avanços no Plano Nacional de Educação (2014) com relação aos Planos anteriores, não apresentando, entretanto, conquistas significativas no que concerne à Educação do Campo. Há, pois, um longo caminho a ser percorrido, antes que se possa afirmar que o Brasil garante o direito educacional para a população campesina. Palavras-chave: Educação do campo. Plano Nacional de Educação. Política pública.

\section{Introdução}

Em um mundo marcado por contrastes, estabelecem-se tensões entre a garantia e a efetivação dos direitos básicos, como à vida, à saúde, à educação, dentre outros. Se, por um lado, há a garantia desses direitos em termos legais, por outro convive-se cada vez mais com a "normalização" da negação dos mesmos, ou a hierarquização em sua garantia.

No Brasil, identifica-se a presença dessa hierarquização, especialmente no que diz respeito ao direito à educação pública. Por exemplo, para a população de

a Universidade Federal de Sergipe (UFS). São Cristóvão, Sergipe, Brasil. 
0 a 3 anos, o direito ao acesso à educação não é garantido de modo eficaz pelo Estado, pois somente $23,2 \%$ dessa população frequenta a escola ${ }^{1}$. Outro exemplo é o direito à educação para a população do campo, pois, convive-se, dentre outros problemas, com a realidade do analfabetismo: dos $8,5 \%$ de analfabetos do país, 20,8\% deles encontram-se em áreas rurais (IBGE, 2013). Nesse sentido, torna-se preocupante o fechamento de escolas do campo, acirrado nos últimos 10 anos (BRASIL, 2014a) ${ }^{2}$. Embora proibido por lei ${ }^{3}$, esse fechamento parece ser uma realidade que se vislumbra para o campo, se consideramos que esta é uma questão silenciada no Plano Nacional de Educação (PNE) para o decênio 2014-2024 (BRASIL, 2014b).

Como ações estatais para a educação básica, podemos elencar a aprovação da Lei de Diretrizes e Bases da Educação (LDB) em 1996 (BRASIL, 1996), os Parâmetros Curriculares Nacionais (PCN), editados pelo Ministério da Educação (MEC) em 1997 (BRASIL, 1997) e a aprovação dos PNE. Ainda que referenciada, no texto desses documentos, a garantia da especificidade da Educação do Campo, as ações implementadas se mantêm tímidas, e, por vezes, inclusive, levam à redução dessa especificidade educativa.

O território rural, "lócus" da Educação do Campo, é protagonista histórico de baixos índices educacionais, conforme dados da Pesquisa Nacional de Educação na Reforma Agrária-PNERA (INEP, 2004) e estudos de Andrade e Di Pierro (2004). Além disso, no campo, ainda encontramos unidades educacionais deterioradas, pessoal pouco qualificado, baixa quantidade de equipamentos e de material pedagógico, escolas sem energia elétrica e água potável, etc.

Em junho de 2014, foi aprovado o PNE (BRASIL, 2014b), o qual define a política nacional de educação do país por uma década. As vinte metas ali estabelecidas representam o compromisso do Estado brasileiro para com a educação da população. Nesse documento, encontram-se explícitas as prioridades do Estado brasileiro com a educação nacional, no que diz respeito à qualidade ${ }^{4}$, estrutura, investimentos financeiros, acesso, permanência e sucesso dos estudantes. A análise desse conjunto de metas permite visualizar a negligência com relação ao campo. É nesse contexto analítico que se insere este artigo teórico, de cunho bibliográfico.

Dados disponíveis em: <http://pne.mec.gov.br/>. Acesso em: 10 out. 2015.

2 Dados disponíveis em: <http://www.mst.org.br>; <http://www1.folha.uol.com.br/educacao/2014/03/1420332pais-fecha-oito-escolas-por-dia-na-zona-rural.shtml>. Acesso em: 29 nov. 2017.

3 Referência à Lei n 12.960/2014 que dispõe sobre o fechamento de escolas no campo (BRASIL, 2014a).

4 Entende-se por qualidade o conjunto de definições relativos à "qualidade social da educação", desenvolvido por Dias Sobrinho (2010) e Silva (2009). 
As reflexões empreendidas foram subsidiadas por um material empírico, composto pelo Plano Decenal de Educação (BRASIL, 1993) e os PNE (BRASIL, 2001, 2014b). A seleção desse material foi intencional, considerando-se que esses documentos expressam o direcionamento da política educacional no país, ao longo de 30 anos, período que coincide com a consolidação do debate da Educação do Campo. Foi esse debate balizador da análise que buscou refletir sobre o seu comparecimento nos documentos analisados. Dessa análise, depreendem-se as tensões que emergem do plano vigente, que oscila entre a garantia e a não efetivação do direito à educação.

$\mathrm{O}$ artigo encontra-se organizado em três seções. A primeira reflete sobre a dicotomia Educação Rural/Educação do Campo, em que se diferenciam, onde se aproximam, quais elementos as distinguem, explicitando os argumentos teóricos a serem utilizados na análise desses documentos. A segunda apresenta uma análise da Educação do Campo nos PNE, com destaque para o plano em vigência, que traça do direcionamento político para a educação do campo nesta década. As conclusões do texto refletem sobre a necessidade de garantia efetiva do direito à educação para a população campesina, diante das reivindicações e demandas da Educação do Campo.

\section{Educação do Campo, Educação Rural: que diferenças, que semelhanças...}

No meio educacional brasileiro, nas últimas duas décadas, são frequentes os questionamentos acerca da Educação do Campo e da Educação Rural, bem como as diferenças e semelhanças entre elas. Esses questionamentos emergem quando o Estado é chamado a assumir, de fato, a educação dos filhos dos trabalhadores do campo, através de uma proposta educativa que garanta o direito constitucional de educação para todos os cidadãos e cidadãs brasileiros(as), e que atenda às demandas históricas da população campesina, visto que esta sempre enfrentou dificuldades para garantir tal direito, pois a estes tem sido dispensando "[...] um tratamento residual o ensino em áreas rurais ao longo da história da educação brasileira" (RIOS, 2016, p. 333). Na tentativa de contribuir para a compreensão dessas duas alternativas educacionais, são destacados aspectos específicos de cada uma.

Tratar da Educação Rural requer recuperar a oferta dessa educação à população campesina. Apesar de haver registro de oferta de Educação Rural já no século XIX, a mesma só é disseminada, de fato, no Brasil, no século XX, contando, então, com objetivos muito bem definidos e alinhados ao modelo econômico brasileiro vigente (RIBEIRO, 2012). É possível identificar a priorização, de uma maneira 
geral, por parte da Educação Rural, de um atendimento a demandas criadas pelos mercados interno e externo, em detrimento da garantia da escolarização do homem e da mulher do campo, o que pode ser reconhecido em três momentos distintos discutidos a seguir.

No período compreendido entre as décadas de 1930/1940, sob a influência do chamado "ruralismo pedagógico", defendia-se uma educação que contribuísse com a fixação do homem/mulher no campo. A proposta visava a uma educação ligada à produção agrícola, ou seja, a escola deveria preparar os filhos dos agricultores para continuar na zona rural. Havia, por parte do Estado, o objetivo de conter o êxodo rural através da escola, que cumpriria o papel de convencer o cidadão a permanecer no meio rural. O "ruralismo pedagógico" consistia

[...] na defesa de uma escola adaptada e sempre referida aos interesses e necessidades hegemônicas. Estes encontram-se diluídos entre o que se pôde perceber como interesses de caráter econômico das classes e grupos de capitalistas rurais ou como interesses de grupos, principalmente políticos interessados na questão urbana (PRADO, 1995, p. 6).

A função da escola rural, naquele momento, além de instruir, constituía auxiliar na adequação do indivíduo ao meio. A Educação Rural possuía como principais objetivos: a "[...] valorização do homem rural, educar é fixar o homem à terra em que vive, é adaptá-lo ao seu meio, formar a mentalidade do homem do campo" (PRADO, 1995, p. 14-15), o que evidencia a intenção do Estado de conter, por meio da escola, as insatisfações campesinas. Por outro lado, tais objetivos confrontavam a visão da sociedade da época, que percebia o homem/mulher do campo como "Jeca".

Os argumentos para conter o êxodo rural eram voltados para a garantia da produtividade do trabalho no campo e, também, para a fixação do trabalhador no seu lugar de origem. Assim, não haveria escassez da mão de obra na zona rural, nem seria gerado um "inchaço" populacional na zona urbana. Ao mesmo tempo, objetivava-se povoar regiões rurais com baixa ocupação populacional. Para garantir os objetivos acima elencados, a escola rural priorizava a formação prática para o trabalho no meio rural, reduzindo, assim, parte do conhecimento escolar, considerado supérfluo. A proposta educacional para o campo era pragmática e "[...] não deveria encher o cérebro de conhecimentos especulativos [o objetivo] é, sim, tornar o indivíduo capaz de adquirir a sabedoria de se aplicar a um trabalho proveitoso" (PRADO, 1995, p. 13). 
Em suma, a Educação Rural se norteava por interesses econômicos e ideológicos, primando, assim, não em garantir uma educação de boa qualidade aos trabalhadores do meio rural, mas qualificá-los para uma permanência obediente, mesmo em condições adversas, visto que não havia investimentos públicos para melhorar a vida nesse território.

A partir da década de 1950, considerado o período "desenvolvimentista", principalmente pela conjuntura de industrialização do Brasil, a ideia de progresso enfatizava uma cultura de supervalorização do mundo urbano, em detrimento do mundo rural. Tal contexto de predomínio da cultura urbana fortaleceu a percepção social das pessoas do meio rural por meio de estereótipos negativos, tais como "tabaréu" "capiau", "caipira", "atrasado", "matuto", dentre outros. Em função dessa percepção, o campesino, além de representar entrave ao desenvolvimento por sua suposta "ignorância" e "ingenuidade", era considerado "presa fácil" para a subversão. Assim, era necessário controle estatal sobre essa população para combater "o comunismo" e garantir o desenvolvimento/progresso da sociedade brasileira.

Por sua vez, a conjuntura internacional do pós Segunda Grande Guerra propiciou ao Brasil o estabelecimento de parcerias internacionais, especialmente, com os Estados Unidos, para garantir o desenvolvimento das populações carentes, incluída aí a população rural. Nesse contexto, foi criada a Campanha Nacional de Educação Rural (CNER), que tinha como principais objetivos "[...] adequar os camponeses ao novo modelo de desenvolvimento para torná-los cidadãos e elevar seus padrões culturais, concebidos pelo programa como atrasados e inferiores do ponto de vista cultural" (BARREIRO, 2006, p. 123).

Para garantir tais objetivos, a CNER foi estruturada em torno de quatro eixos: Estudos e Pesquisas; Treinamento; Missões Rurais e Divulgação (BARREIRO, 2006). As missões rurais podem ser consideradas "o carro-chefe" da CNER. As equipes eram compostas por:

[...] médico agrônomo, assistente social, educador; além de dentista, veterinário, enfermeira, agente de economia doméstica, técnico de rádio, técnico de cinema, motorista e outros especialistas, dependendo das necessidades, as missões rurais empregavam quatro técnicas principais de trabalho: a organização de comunidade, o serviço social de grupo, a educação sanitária, a extensão agrícola e o cooperativismo (BARREIRO, 2010, p. 53).

Havia, nesse período, um processo de transformação da vida dos campesinos, que incluía, desde a construção, organização e decoração de sua casa, até auxílio 
na forma de se comunicar em público. Tal processo era idealizado e executado a partir de propostas educativas que atendiam aos interesses do Estado Brasileiro, orientado e assessorado por organismos internacionais, a exemplo da Organização das Nações Unidas (ONU) e da Cooperativa Americana de Remessas para o Exterior (CARE). A participação dos campesinos se restringia a aprender e implementar o que esses "missioneiros" ensinavam. Aliada ao modelo econômico, a escola rural tinha como função primordial civilizar os campesinos, para que não se constituíssem como empecilho ao desenvolvimento e progresso do país (BARREIRO, 2010, 2013). Importante destacar a dificuldade em cumprir tal função através da educação, até porque não eram todos que tinham acesso a processos educativos. O país enfrentava dificuldade na adequação educacional às necessidades socioculturais, especialmente, a educação primária urbana $\mathrm{e}$ rural (FERNANDES, 2013). No entanto, não se pode desconsiderar que havia pretensões nesse sentido.

Nas décadas de 1960/1970, a Educação Rural é demarcada, a exemplo do período anterior, por programas com influência estadunidense, com vistas ao fortalecimento da concepção de comunidade e integração, pautadas em projetos integradores que contemplavam, entre suas ações, a educação para o desenvolvimento comunitário. As disparidades regionais, o modelo latifundiário e o interesse dos Estados Unidos em investir em assessoria técnica e financeira na América Latina, formaram o contexto propício para a criação da Superintendência do Desenvolvimento do Nordeste (SUDENE), "[...] primeiro órgão do planejamento e desenvolvimento regional brasileiro" (CALAZANS, 1993, p. 29).

A concepção é ainda desenvolvimentista, mas voltada, nesse momento, para programas educacionais que atendessem às necessidades específicas a cada contexto regional. Quanto à educação, cabe mencionar que

[...] é planejada, estruturada e realizada a partir das necessidades educacionais de cada região. Não há uma superestrutura válida para todo e qualquer meio ambiente. As exigências de planejamento e efetivação da educação rural estão correlacionadas à política do desenvolvimento e transformação das estruturas do setor primário. O modelo de desenvolvimento é uma variável que interfere no estabelecimento de diretrizes e políticas para a educação rural, afirmavam os planejadores de educação e recursos humanos da época (CALAZANS, 1993, p. 30).

Nessas duas décadas, especialmente no início da década de 1960, havia uma profusão de debates sobre os reais objetivos da Educação Rural. Uma das vertentes 
afirmava que o papel da educação seria “[...] propor elementos para que o homem, ao invés de subordinar-se, ingresse nesse mundo inovado e consiga situar-se nele como no seu mundo, e definir o papel que nele lhe compete" (CALAZANS, 1993, p. 36).

Outra vertente que prevalece nos programas educativos daquela época considerava como elementos fundamentais na educação sua eficácia e custos sociais, políticos e financeiros. Para Calazans (1993), o que interessava saber, em relação à educação, era "[...] como a educação é veículo de transformação econômica e política, e por que meios, em que tempo, com que intensidade atua sobre os outros processos" (p. 36). Há, de acordo com a autora, nas duas vertentes, uma compreensão do rural como "atraso e entrave" ao desenvolvimento, e, para sua superação, a alternativa seria a imposição de programas educativos objetivando mudanças profundas nos valores, atitudes, comportamentos, desconsiderando qualquer princípio previamente consolidado entre os campesinos e o mundo rural, e enfatizando a relação de consumo e dependência dos agricultores. Assim,

[...] a educação rural e a formação dos engenheiros e técnicos agrícolas, no Brasil, foram usadas como instrumentos educativos do capital para a expropriação da terra combinada à proletarização do agricultor, e para a constituição de um mercado consumidor de produtos agrícolas industrializados, associada à geração de dependência dos agricultores em relação a esses produtos (RIBEIRO, 2010, p. 180).

Nesse sentido, os programas educativos, seja na formação profissionalizante ou na assistência técnica e extensão rural, contribuíram, de forma efetiva, para a formação de um grande mercado consumidor dos produtos industrializados (pesticidas, adubos, equipamentos) atendendo aos interesses externos. Foram, também, eficazes no estímulo a mudanças nas formas de produção agrícola, aproximando/transformando o mundo rural produtor de alimentos do/no mundo do capital produtivo da monocultura. Gritti (2007) atribui as transformações ocorridas nesse período à "Revolução Verde" e acredita que, no desenvolvimento desse programa, as "[...] estruturas tradicionais comunitárias tornaram-se dependentes de uma tecnologia que não controlavam e não produziam" (p. 31). Ressalta-se, além disso, que as consequências do programa incluíam empobrecimento do solo e da biodiversidade, e aumento das pragas das plantas. Ainda assim, a escolarização dos trabalhadores rurais foi direcionada para esse modelo de agricultura.

\footnotetext{
Introdução em grande escala de cultivos modernos de alta produtividade. Programa liderado por ideários norte- americanos, que se baseavam na previsão de uma catástrofe alimentar, ocasionada por uma crise na produção de grãos e paralelo crescimento demográfico na América Latina, Ásia e África (GRITTI, 2007).
} 
A década de 1980 no Brasil protagonizou significativas mudanças e novos ordenamentos no quadro político, como a reabertura política do país com o fim da ditadura militar. Nesse período, o país enfrentava os efeitos da crise internacional, que afetou todos os setores produtivos. A inflação, o desemprego, os baixos salários, a dívida externa e o endividamento do setor público compunham o cenário propício para impulsionar mudanças na sociedade brasileira.

No campo, a agricultura enfrentava dificuldade de aceitação de sua produção no mercado internacional, além de apresentar dependência de subsídios do governo e financiamentos bancários, bem como de tecnologia, cuja carência derivava, principalmente, das influências estrangeiras anteriormente discutidas. A educação não ficou imune a essa conjuntura e "[...] foi severamente prejudicada pela ausência de investimentos no aparelhamento da escola e na qualificação dos professores" (GRITTI, 2007, p. 32).

Por sua vez, a conjuntura econômica recessiva e o enfraquecimento do regime militar se constituíram em oportunidade para o surgimento de novas organizações da sociedade civil e da sociedade política. Na educação, podemos destacar a criação da Associação Nacional dos Docentes do Ensino Superior (ANDES) em 1981, o Fórum Nacional de Defesa da Escola Pública, 1987, e o Movimento em Defesa da Escola Pública, 1988 (GOHN, 2009). No campo, há a criação do Movimento dos Trabalhadores Sem Terra (MST), em 1984, o que irá propiciar a construção coletiva, junto a outros movimentos sociais e sindicais do campo, de uma proposta de educação que se contrapunha à Educação Rural.

Na última década do século XX, o Brasil incorpora a política neoliberal nos debates políticos e na política nacional de modo geral. As primeiras evidências de tal incorporação são identificadas a partir das ações de abertura de nossas fronteiras para a globalização, e sua consolidação se dá a partir de 1995, com a submissão do Brasil às ordens do Fundo Monetário Internacional (FMI), sob o pleito de incluir o país no assim chamado "primeiro mundo" (LOUREIRO, 2003; HADDAD, 2008).

No campo, a política agrária tinha, a exemplo de décadas anteriores, os Estados Unidos como referência. Assim, objetivava-se seguir o modelo de agricultura daquele país. Para Loureiro (2003), o modelo de agricultura adotado no Brasil apresentava as seguintes características: abertura para o mercado externo, ausência do setor público na agricultura, estímulo às grandes fazendas, integração seletiva dos pequenos agricultores na agroindústria, desaparecimento da agricultura familiar de subsistência, maior atenção ao capital e à tecnologia, menor preocupação com a terra, entre outras. 
A implantação desse modelo de agricultura no país gerou severos impactos para o campo, atingindo, desde o aspecto econômico, até questões sociais e culturais. Dentre esses impactos, podemos destacar a concentração da terra, a marginalização econômica e social da agricultura familiar, o desemprego rural, a dependência do país aos produtos agrícolas importados, dentre outros.

A conjuntura agrária do Brasil, no final do século XX, mostra que a modernização conservadora ampliou sua área de ação, concomitantemente, intensificou-se a pressão dos movimentos sociais do campo sobre o Estado. Em 1998 foram registrados "[...] mais de mil conflitos espalhados por todo o país" (OLIVEIRA, 2001, p. 197). Vale destacar que a violência no campo, nesse período, assume um formato diferenciado, à medida que esses confrontos passam a ser protagonizados por representantes do próprio Estado, via repressão policial (OLIVEIRA, 2001, 2007).

No campo educacional, estava em curso um processo de reformas educacionais, que incluiu a aprovação da LDB n ${ }^{\circ}$ 9.394/1996 e os PCN e a criação do Fundo de Manutenção e Desenvolvimento do Ensino Fundamental e de Valorização do Magistério (FUNDEF). Junto à implementação dessas reformas educacionais - que garantiam o direito de educação pública gratuita para todos, igualdade de condições e permanência na escola, respeito ao pluralismo de ideias e de concepções - cresce a valorização da escola privada em detrimento da escola pública e se acelera, portanto, o processo de precarização da educação pública (GOHN, 2009; SINGER, 1996).

$\mathrm{Na}$ zona rural, a precarização das escolas assume caráter ainda mais grave. No início do século XX, uma pesquisa do Instituto Nacional de Estudos e Pesquisas Educacionais Anísio Teixeira (Inep) realizada, em 2004, nos assentamentos de reforma agrária, mostrou que, das 8.679 escolas existentes em assentamentos, $84 \%$ delas ofereciam apenas os anos iniciais do ensino fundamental e atendiam somente $51 \%$ da demanda estudantil para essa modalidade. Em 56\% dessas escolas não havia diretor, e os professores residiam em outras localidades, geralmente nas sedes dos municípios, e não possuía identidade com a cultura campesina, condição imprescindível para garantir uma boa Educação do Campo de acordo com o "Movimento por uma Educação do Campo". Em relação ao tamanho da escola, $49 \%$ tinham somente uma sala de aula, e em $44 \%$ não havia ambiente do tipo biblioteca ou sala de leitura, nem equipamentos como estantes, armários ou caixas para guardar e ou disponibilizar os livros e material de leitura para os(as) alunos(as). A pesquisa mostrou, ainda, que $21 \%$ das escolas em áreas de reforma agrária não tinham energia elétrica nem qualquer outro tipo de fonte de iluminação, e que somente em $68 \%$ delas era garantida água filtrada para os estudantes (INEP, 2004). 
É nesse contexto de enfrentamento dos trabalhadores com o Estado, reivindicando direitos básicos como trabalho (terra), saúde, moradia, crédito e educação, que começa a ser formatada uma proposta de educação identificada cultural e socialmente com o território que os trabalhadores reconhecem como campo. No marco histórico de seu surgimento, encontram-se dois eventos promovidos pelo MST, em parceria com a Universidade de Brasília (UnB), com a Conferência Nacional dos Bispos do Brasil (CNBB), a Organização das Nações Unidas para Educação, Ciência e Cultura (UNESCO), e o Fundo das Nações Unidas para a Infầncia (UNICEF): o $1^{\circ}$ Encontro Nacional de Educadoras e Educadores da Reforma Agrária (ENERA), realizado em 1997, e a $1^{a}$ Conferência Nacional por uma Educação Básica do Campo, de 1998.

O primeiro ENERA é encerrado com o documento intitulado "Manifesto das Educadoras e dos Educadores da Reforma Agrária ao Povo Brasileiro" (REFORMA AGRÁRIA EM DADOS, 1997). Nesse manifesto, os(as) educadores(as) afirmam a importância da educação como instrumento indispensável para a transformação da sociedade, que classificam como excludente e injusta. Destacam, ainda, uma escola "[...] que desperte os sonhos de nossa juventude, que cultive a solidariedade, a esperança, o desejo de aprender e ensinar sempre e de transformar o mundo" (CALDART, 2003, p. 80). O texto do manifesto é mais reivindicativo do que propositivo. A proposta de Educação do Campo mais orgânica é objeto da $1^{a}$ Conferência Nacional Por uma Educação Básica do Campo (KOLLING; NERY; MOLINA, 1999).

Essa conferência anuncia que é necessária uma educação para a população do campo diferente da que havia até então. Com fortes marcas do mundo urbano, a educação, nas escolas do campo, vivenciava um processo de marginalização, relegada ao abandono pelos governos municipais e estaduais, que ignoravam o campo ou o identificavam como atraso e empecilho ao desenvolvimento. Considerada como "resíduo" do sistema educacional, a Escola do Campo adotava um currículo alheio às demandas do campo, que estimulava o abandono do campo ao tratar o urbano como superior ao rural (KOLLING; NERY; MOLINA, 1999). Nesse sentido, a educação que se constituísse como instrumento de superação dessa realidade deveria ter características bem diversas.

Em linhas gerais, podemos identificar cinco princípios da proposta de Educação do Campo que o texto da Conferência apresenta como transformações necessárias à escola do campo.

A primeira transformação é no papel da escola. Desse papel advém o compromisso com a intervenção social, através do reconhecimento de projetos de desenvolvimento regionais como instrumento de formação para o trabalho do 
campo, e o compromisso com a cultura do povo do campo, por meio do respeito, reconhecimento e fortalecimento de processos que resgatam, preservam e recriam os valores culturais dos povos do campo (KOLLING; NERY; MOLINA, 1999).

A segunda relaciona-se à gestão das escolas como espaço público e democrático. É necessária, assim, a criação de processos de gestão que ampliem a participação dos sujeitos (alunos, professores, pais, gestores, comunidade) tanto nas decisões, como nas proposituras que levem a transformações do cotidiano escolar educativo.

A terceira, por sua vez, seria na orientação pedagógica da escola. É fundamental a escola do campo se referenciar nas experiências da educação popular, incorporando outras formas de ensinar e aprender, outros processos educativos que acontecem fora dos muros da escola.

Uma quarta transformação diz respeito aos currículos escolares. O currículo da escola do campo deve ter como central a formação humana, priorizar a relação do trabalho na terra como forma de fortalecer a identidade campesina, independente da atividade profissional que o cidadão opte em exercer. O currículo precisa incorporar, no processo educativo escolar, a relação educação e cultura, e garantir a estudantes conhecimento das diversas formas de manifestações culturais, mas principalmente a cultura campesina.

Por fim, a quinta se relaciona aos professores e professoras do campo que, segundo Kolling, Nery, Molina (1999), historicamente, são preteridos pelo sistema educacional em sua estima, condições de trabalho, desvalorização profissional, entre outros, e que repassam essa baixa expectativa para seus alunos, nesse caso, crianças, jovens e adultos do campo. Uma nova postura pedagógica, a construção de outros elos entre professores e comunidades campesinas se fazem necessárias para garantir uma Educação do Campo que atenda às demandas dessa população.

Podem-se destacar, também, algumas conquistas efetivas, principalmente no âmbito de regulamentação da proposta de Educação do Campo como política pública de educação. São exemplos disso: a criação do Programa Nacional de Educação na Reforma Agrária (Pronera), em 1998; a aprovação pelo Conselho Nacional de Educação das Diretrizes Operacionais para a Educação Básica nas Escolas do Campo, em 2001; o valor diferenciado para o custo aluno do campo, previsto no Fundo de Manutenção e Desenvolvimento da Educação Básica e de Valorização dos Profissionais da Educação (Fundeb) em 2007; o Procampo/2009 para formação de professores do campo; e o Pronacampo/2013, que institui a Política Nacional de Educação do Campo (MEC, 2013). 
O próximo passo se constituiria em consolidar, nos sistemas educacionais, a Educação do Campo, conforme demandada e reivindicada pelos movimentos sociais e aprovada pelas instâncias governamentais e normativas do país. Nesse contexto, o PNE (2014-2024) (BRASIL, 2014b) é importante instrumento na consolidação da Educação do Campo e na superação da Educação Rural, que nega aos povos o direito a uma educação que considere a terra, a cultura e o trabalho como basilares da proposta educativa para as escolas do campo.

A trajetória da educação do campo/rural traçada, até então, parece evidenciar nas propostas pedagógicas intenções e objetivos que levem, através de processos educativos escolares ou profissionalizantes, os sujeitos à subordinação, acomodação, aceitação do status quo. Nesse sentido, alguns destaques são necessários: a educação por si só não produz efeitos tão contundentes. O próprio movimento por educação do campo pode ser considerado como efeito contrário às políticas de educação rural. Nos diferentes contextos sociais, inclusive no campo, as políticas públicas não são aceitas de forma homogênea sem resistência, mas geram impactos significativos, portanto, mesmo sem ter sido implementado plenamente, os planos nacionais de educação se constituem num conjunto de políticas importantes para a educação brasileira e para a educação do campo especialmente.

\section{Educação do Campo e Plano Nacional de Educação}

De modo a compreender, no campo das políticas públicas, o nível de prioridade conferido pelo Estado, é importante analisar a forma como cada demanda é prevista nos documentos executivos. O conjunto de leis e regulamentos educacionais da década de 1990 com objetivo de fortalecer a escola pública (LDB, PCN, PNE) tem gerado resultados significativos. Apesar dos PNE terem tido pouca execução prática no avanço da qualidade da educação brasileira, bem como constituírem-se como documentos para divulgação pública, consideram-se esses instrumentos de política um meio de a população exigir do Estado melhorias educacionais, mesmo em período de recessão, como o que vivemos atualmente. Assim, esta seção visa a discutir a forma como a Educação do Campo comparece nos PNE. Para tanto, centramos esta análise nos três últimos planos $(1993,2001,2014)$.

Após participar, em 1990, da Conferência Educação para Todos, em Jomtien, e assumir o compromisso de assegurar a educação de qualidade como um direito de todos/as, fortalecendo o que já era garantido na constituição de 1988, o Brasil, através do MEC, apresenta, em 1993, o Plano Decenal de Educação com vigência entre 1993-2003. O texto do plano apresenta-se como "[...] conjunto de diretrizes de política em processo contínuo de atualização e negociação" (BRASIL, 1993, p. 40). A Educação do Campo (rural à época) comparece na estratégia f do 
segundo objetivo do plano, na qual se afirma o compromisso de universalizar, com equidade, as oportunidades educacionais e de manter níveis apropriados de aprendizagem para crianças de áreas rurais pobres. A intenção no texto do plano, em relação a esse objetivo, é a garantia da universalização por meio da diferenciação de métodos, estratégias educativas e modalidades apropriadas às necessidades desses grupos, garantindo-se, desse modo, tanto o acesso à educação quanto à qualidade da escola (BRASIL, 1993).

O sexto objetivo do texto, que pretende "[...] incrementar recursos financeiros para manutenção e investimentos na qualidade da educação básica" (BRASIL, 1993, p. 40), apresenta a Educação do Campo referendada na estratégia b, que prevê a criação de fundos e mecanismos não convencionais de financiamento a projetos inovadores em áreas de grandes concentrações demográficas de pobreza, incluídas as "áreas rurais críticas". Por último, cabe registrar a referência à Educação do Campo no Plano Decenal no tópico "metas globais". Em uma relação de doze metas, a antepenúltima contém o seguinte texto: "[...] dotar todas as escolas de ensino fundamental, urbanas e rurais, estaduais e municipais, de condições básicas de funcionamento" (BRASIL, 1993, p. 43).

O Plano Decenal de Educação teve pouca efetividade prática, por isso a crítica de que o mesmo nem foi implementado (AGLIARDI; WELTER; PIEROSAN, 2012). Por sua vez, como documento que pretendia se constituir na Política Nacional de Educação para Todos, em dez anos, desconsiderava parte desse "todos", como a população campesina, ao apresentá-la, no texto legal, de forma secundarizada e pouco objetiva.

O PNE (2001-2011) (BRASIL, 2001) foi aprovado em condições bem diversas do Plano Decenal anterior. Esse PNE foi transformado na Lei $\mathrm{n}^{\circ} 10.172$, de janeiro de 2001, após um processo de intenso debate e tensão política no congresso nacional. A sociedade civil, através do Fórum Nacional em Defesa da Escola Pública, reivindicava, desde o processo constituinte, um projeto educacional que garantisse à população brasileira uma educação como direito de todos. Nesse sentido, foram realizados, em 1996 e 1997, dois Congressos Nacionais de Educação (CONED), para elaboração da proposta.

A consequência desse movimento, no dia 10 de fevereiro de 1998, foi a apresentação à Câmara dos Deputados do chamado PNE da sociedade civil. No dia seguinte, o governo protocolou outro projeto de PNE. O trâmite de duas propostas de PNE configurava, naquele momento, a "[...] existência de dois projetos de escola, duas propostas opostas de política educacional; elas de fato traduziam dois projetos antagônicos de país" (VALENTE, 2001, p. 11). 
O PNE aprovado versava sobre os seguintes eixos: "a) a educação como direito individual; b) a educação como fator de desenvolvimento econômico e social; c) a educação como meio de combate à pobreza" (AGUIAR, 2010, p. 710). O embate travado entre o governo e as entidades civis, principalmente de profissionais da educação, durante os três anos de tramitação dos dois projetos na Câmara, levou à incorporação de algumas das metas e objetivos do projeto da sociedade civil. Entretanto, ao serem incorporadas, assumiam redação ambígua, sem definição precisa de execução ou de responsabilização. A dualidade de linguagem, utilizada no texto do plano, é exemplificada por Valente (2001, p. 15) na meta 20: "Eliminar a existência, nas escolas, de mais de dois turnos diurnos e um turno noturno, sem prejuízo do atendimento da demanda".

A Educação do Campo já havia marcado seu surgimento com a realização do $1^{\circ}$ ENERA (1997), da $1^{a}$ Conferência por uma Educação Básica do Campo (1998) e a criação do Pronera (1998). Entretanto, o MEC manteve-se apartado dessa construção. O primeiro Pronera foi criado pelo Ministério Extraordinário de Política Fundiária e incorporado ao Instituto Nacional de Colonização e Reforma Agrária (INCRA), em 2001, onde ainda se encontra. Portanto, o PNE (2001-2011) (BRASIL, 2001) permaneceu com a concepção de Educação Rural no texto, ignorando o termo Educação do Campo e seus desdobramentos.

Torna-se importante destacar que a prioridade política do PNE é fundamentada em uma ideia de educação urbana. Nesse sentido, o conjunto de objetivos e metas tinha, como foco central, as marcas e características de uma educação que atendesse às demandas e necessidades da população urbana. Como o direito constitucional de educação é para "todos", o silêncio desse direito no PNE às populações do campo evidencia não cumprimento das obrigações do Estado. Dessa forma, a Educação do Campo aparece no texto do PNE (2001-2011) (BRASIL, 2001) apenas de forma genérica e pouco objetiva. Em uma das diretrizes do ensino fundamental, que diz respeito, exclusivamente, à Educação do Campo, a generalidade e ausência de objetividade, em se tratando de uma política nacional de educação com tempo de execução definido, mantêm-se:

A escola rural requer um tratamento diferenciado, pois a oferta de ensino fundamental precisa chegar a todos os recantos do País e a ampliação da oferta de quatro séries regulares em substituição às classes isoladas unidocentes é meta a ser perseguida, consideradas as peculiaridades regionais e a sazonalidade (VALENTE, 2001, p. 72). 
Além dessa diretriz, apresentam-se, ainda, três objetivos e metas do ensino fundamental com foco específico na Educação do Campo. A meta quinze, que previa a transformação das escolas unidocentes em escolas com mais de um professor; a meta dezesseis pretendia promover a associação de classes unidocentes (multisseriadas) em escolas com, um mínimo, de quatro séries; a meta dezessete, previa a garantia de transporte escolar para a zona rural, quando necessário. As metas não estavam relacionadas à especificidade da Educação do Campo no que diz respeito à cultura campesina, à produção de conhecimento ou ao currículo, entretanto, destaca-se, no PNE (2001-2011) (BRASIL, 2001), a presença de metas específicas para a educação da população campesina.

Em junho de 2014, mesmo tendo sido objeto de debates e proposituras nos diversos segmentos da sociedade desde 2010, foi aprovado e sancionado, sem apresentar avaliação do desempenho do plano anterior ou diagnóstico que demonstre a qualidade da educação brasileira para além dos dados quantitativos, o novo PNE para o decênio 2014-2024 (BRASIL, 2014b). Para Souza (2014), o debate em torno da educação para a próxima década, centrou-se na ampliação do financiamento da educação para $10 \%$ do produto interno bruto (PIB). Um diagnóstico qualitativo seria fundamental no planejamento de uma política pública, especialmente uma política nacional de educação para uma década. É através do diagnóstico que é possível estabelecer metas, definir prioridades e financiamento para determinada política pública.

Um diagnóstico evidenciaria, por exemplo, a potencialidade do PNE para atingir a meta um, que objetiva a universalização da educação infantil na pré-escola até o ano 2016. A partir desse diagnóstico, seria possível mensurar o desafio e o investimento para o Estado de tal meta, o que é, inclusive, imprescindível no caso da Educação Infantil do Campo, na qual se identifica a intensificação do fechamento das escolas, o que pode levar as famílias a não matricularem as crianças dessa faixa etária na escola, em função das distâncias a serem percorridas diariamente.

Essas e outras questões nos levam a uma análise mais cuidadosa na perspectiva de considerar o novo PNE como um instrumento de política pública da educação que objetiva enfrentar desafios e elevar a qualidade da educação brasileira. Estruturado em metas e estratégias, esse PNE elege como diretriz:

Erradicação do analfabetismo; Universalização do atendimento escolar; Superação das desigualdades educacionais; Melhoria da qualidade do ensino; Formação para o trabalho e para a cidadania; Promoção do princípio da gestão democrática da educação; Promoção humanística, 
científica, cultural e tecnológica do País; Estabelecimento de meta de aplicação de recursos públicos em educação como proporção do produto interno bruto, que assegure atendimento às necessidades de expansão, com padrão de qualidade e equidade; Valorização dos profissionais da educação e; Promoção dos princípios do respeito aos direitos humanos e à sustentabilidade socioambiental (BRASIL, 1993, p. 40).

Observando as dez diretrizes que orientam as metas e estratégias desse documento, não se vislumbra nenhuma que contemple, especificamente, a educação da população campesina. Uma análise mais cuidadosa pode mostrar a inclusão dessa população na linguagem generalizada do texto do plano. O mesmo ocorre nas metas estabelecidas pelo plano. Das vinte que compõem o corpo do texto do PNE, apenas uma versa sobre a Educação do Campo. Torna-se relevante refletir que, com a primeira diretriz voltada para a erradicação do analfabetismo, sendo o campo detentor de $23,3 \%$ de analfabetos em contrapartida aos $7,6 \%$ da área urbana (MOLINA, 2011). A ausência de metas específicas para garantir a educação da população campesina é, no mínimo, questionável.

A quarta diretriz, que fundamenta as metas do PNE e trata da melhoria da qualidade do ensino, deveria pressupor a necessidade de elaboração de metas específicas para o campo, que apresenta os índices de qualidade da educação escolar mais precários. Da mesma forma, a diretriz de superação das desigualdades educacionais exige metas específicas para o campo, haja vista, por exemplo, a situação do analfabetismo já citada.

Nos Quadros 1 e 2, é possível conferir as "prioridades" na política educacional brasileira, com relação à Educação do Campo, nos três últimos PNE.

Quadro 1. Educação do Campo/Plano Decenal de Educação (1983) e PNE (2001-2011) (BRASIL, 2001).

\begin{tabular}{|c|l|}
\hline \multicolumn{2}{|c|}{ Plano Decenal de Educação (1993) } \\
\hline \multirow{2}{*}{ Objetivos } & $\begin{array}{l}\text { Universalizar, com equidade, as oportunidades de alcançar e manter níveis } \\
\text { apropriados de aprendizagem e desenvolvimento. }\end{array}$ \\
\cline { 2 - 3 } & $\begin{array}{l}\text { Incrementar os recursos financeiros para manutenção e para investimentos na } \\
\text { qualidade da educação básica, conferindo maior eficiência e equidade em sua } \\
\text { distribuição e aplicação. }\end{array}$ \\
\hline \multirow{2}{*}{ Diretrizes } & $\begin{array}{l}\text { Plano Nacional de Educação (2001-2011) } \\
\text { A escola rural requer um tratamento diferenciado, pois a oferta de ensino } \\
\text { de quatro séries regulares em substituição às classes isoladas unidocentes é } \\
\text { meta a ser perseguida, consideradas as peculiaridades regionais e sazonalidade. }\end{array}$ \\
\hline
\end{tabular}

Fonte: Elaboração própria (2016). 
Quadro 2. Educação do Campo no PNE (2014-2024) (BRASIL, 2014b)ํ.

\begin{tabular}{|c|}
\hline Plano Nacional de Educação (2014-2024) \\
\hline Estratégias e Meta \\
\hline $\begin{array}{l}\text { 1.10 Fomentar o atendimento das populações do campo e das comunidades indígenas } \\
\text { e quilombolas na educação infantil nas respectivas comunidades, por meio do } \\
\text { redimensionamento da distribuição territorial da oferta, limitando a nucleação de escolas } \\
\text { e o deslocamento de crianças, de forma a atender às especificidades dessas comunidades, } \\
\text { garantido consulta prévia e informada. }\end{array}$ \\
\hline $\begin{array}{l}\text { 2.6 Desenvolver tecnologias pedagógicas que combinem, de maneira articulada, a } \\
\text { organização do tempo e das atividades didáticas entre a escola e o ambiente comunitário, } \\
\text { considerando as especificidades da educação especial, das escolas do campo e das } \\
\text { comunidades indígenas e quilombolas; } \\
\text { 2.10 Estimular a oferta do ensino fundamental, em especial dos anos iniciais, para as } \\
\text { populações do campo, indígenas e quilombolas, nas próprias comunidades. }\end{array}$ \\
\hline
\end{tabular}

3.7 Fomentar a expansão das matrículas gratuitas de ensino médio integrado à educação profissional, observando-se as peculiaridades das populações do campo, das comunidades indígenas e quilombolas e das pessoas com deficiência;

3.10 Fomentar programas de educação e de cultura para a população urbana e do campo de jovens, na faixa etária de 15 (quinze) a 17 (dezessete) anos, e de adultos, com qualificação social e profissional para aqueles que estejam fora da escola e com defasagem no fluxo escolar;

4.3 Implantar, ao longo deste PNE, salas de recursos multifuncionais e fomentar a formação continuada de professores e professoras para o atendimento educacional especializado nas escolas urbanas, do campo, indígenas e de comunidades quilombolas.

5.5 Apoiar a alfabetização de crianças do campo, indígenas, quilombolas e de populações itinerantes, com a produção de materiais didáticos específicos, e desenvolver instrumentos de acompanhamento que considerem o uso da língua materna pelas comunidades indígenas e a identidade cultural das comunidades quilombolas.

6.7 Atender às escolas do campo e de comunidades indígenas e quilombolas na oferta de educação em tempo integral, com base em consulta prévia e informada, considerando-se as peculiaridades locais.

7.13 Garantir transporte gratuito para todos (as) os (as) estudantes da educação do campo na faixa etária da educação escolar obrigatória, mediante renovação e padronização integral da frota de veículos, de acordo com especificações definidas pelo Instituto Nacional de Metrologia, Qualidade e Tecnologia - Inmetro, e financiamento compartilhado, com participação da União proporcional às necessidades dos entes federados, visando a reduzir a evasão escolar e o tempo médio de deslocamento a partir de cada situação local; 7.14 Desenvolver pesquisas de modelos alternativos de atendimento escolar para a população do campo que considerem as especificidades locais e as boas práticas nacionais e internacionais;

7.27 Desenvolver currículos e propostas pedagógicas específicas para educação escolar para as escolas do campo e para as comunidades indígenas e quilombolas, incluindo os conteúdos culturais correspondentes às respectivas comunidades e considerando o fortalecimento das práticas socioculturais e da língua materna de cada comunidade indígena, produzindo e disponibilizando materiais didáticos específicos, inclusive para os(as) alunos(as) com deficiência.

\section{Continua}

\footnotetext{
1 O quadro é composto por estratégias e uma meta para a Educação do Campo.
} 
Continuação

META: Elevar a escolaridade média da população de 18 (dezoito) a 29 (vinte e nove) anos, de modo a alcançar, no mínimo, 12 (doze) anos de estudo no último ano de vigência deste Plano, para as populações do campo, da região de menor escolaridade no País e dos $25 \%$ (vinte e cinco por cento) mais pobres, e igualar a escolaridade média entre negros e não negros declarados à Fundação Instituto Brasileiro de Geografia e Estatística (IBGE).

\section{Estratégias}

10.3 Fomentar a integração da educação de jovens e adultos com a educação profissional, em cursos planejados, de acordo com as características do público da educação de jovens e adultos e considerando as especificidades das populações itinerantes e do campo e das comunidades indígenas e quilombolas, inclusive na modalidade de educação a distância.

11.9 Expandir o atendimento do ensino médio gratuito integrado à formação profissional para as populações do campo e para as comunidades indígenas e quilombolas, de acordo com os seus interesses e necessidades.

12.13 Expandir atendimento específico a populações do campo e comunidades indígenas e quilombolas, em relação a acesso, permanência, conclusão e formação de profissionais para atuação nessas populações.

14.5 Implementar ações para reduzir as desigualdades étnico-raciais e regionais e para favorecer o acesso das populações do campo e das comunidades indígenas e quilombolas a programas de mestrado e doutorado.

15.5 Implementar programas específicos para formação de profissionais da educação para as escolas do campo e de comunidades indígenas e quilombolas e para a educação especial.

18.6 Considerar as especificidades socioculturais das escolas do campo e das comunidades indígenas e quilombolas no provimento de cargos efetivos para essas escolas.

Fonte: Elaboração própria (2016).

Quando analisamos a Educação do Campo presente nos dois Planos Nacionais de Educação, evidencia-se a pouca importância que o Estado Brasileiro atribuía à educação dessa população. A linguagem genérica e sem objetividade do Plano Decenal de Educação (BRASIL, 1993) é superada pela objetividade do PNE (2001-2011) (BRASIL, 2001), que, ainda assim, conta com evidente priorização pela educação urbana. A Educação do Campo, como apresentada no plano, é posta como um problema a ser enfrentado, ou seja, é objetivo do plano eliminar as classes unidocentes, ao invés de potencializá-las. Entretanto, não há, no PNE, metas ou estratégias que apontem para o enfrentamento da baixa qualidade das classes unidocentes, considerando a especificidade populacional do meio rural. Há, ao invés disso, a eliminação das classes, o que para muitas comunidades campesinas corresponde ao fechamento da escola, como ocorreu no Município de Poço Redondo, sertão sergipano, na última década (VIEIRA et al., 2012).

Da mesma forma, o transporte escolar, presente no PNE (2001-2011) (BRASIL, 2001) como objetivo e meta, tem sido usado como forma de redução da oferta da 
Educação do Campo, à medida que retira crianças e jovens de suas comunidades para estudar em escolas nas sedes dos municípios, ou em comunidades muito distantes de suas residências. Assim, elimina-se a especificidade da Educação do Campo, que tem como um de seus princípios o fortalecimento identitário e cultural das crianças e jovens em suas comunidades.

A partir do Quadro 2, é possível identificar um avanço, no que diz respeito ao campo, no PNE (2014-2024) (BRASIL, 2014b) com relação aos planos anteriores, tendo em vista que a própria linguagem adotada no texto incorpora o termo "Educação do Campo". Nesse sentido, é o primeiro plano que respeita a representatividade do termo em detrimento do anterior (Educação Rural).

Em termos quantitativos, esse PNE assume mais compromisso com a Educação do Campo, à medida que apresenta mais estratégias que os anteriores. Nos PNE (1993-2001) (BRASIL, 2001), as metas ou estratégias não totalizaram cinco, enquanto no PNE (2014-2024) (BRASIL, 2014b), das 254 estratégias, 17 tratam sobre a Educação do Campo, quilombola e indígena. Observa-se, entretanto, que apenas a meta oito da Educação de Jovens e Adultos (EJA) faz referência à Educação do Campo, especificamente, ao estabelecer elevação da escolaridade dos jovens e adultos camponeses.

Destaca-se que o PNE vigente impõe exigências imediatas para as instâncias federativas (União, estados e municípios), a exemplo da criação do Sistema Nacional de Educação em até dois anos de vigência do plano. Outra imposição imediata diz respeito à elaboração dos planos estaduais e municipais de educação. Diferentemente dos planos anteriores, esse obriga estados e municípios a elaborarem seus respectivos planos em até um ano de sua vigência. A Educação do Campo compõe o conjunto de exigências para os Estados e Municípios na elaboração dos planos, conforme artigo oitavo (BRASIL, 2014b).

No PNE (2014-2024) (BRASIL, 2014b), a Educação do Campo é colocada de forma mais evidente, em relação aos planos anteriores, entretanto, como política pública de educação não apresenta avanços significativos em termos de garantia na elevação da qualidade da educação para a população do campo. Um exemplo do pouco avanço do PNE para a educação do campo pode ser evidenciado pela ausência de metas e/ou estratégias para o desafio do ensino multisseriado.

A maioria das escolas multisseriadas, atualmente, estão localizadas no campo (PARENTE, 2014; SANTOS, 2013; HAGE, 2006). A multissérie não é objeto de atenção do PNE (2014-2024) (BRASIL, 2014b), seja para sua manutenção, 
seja para sua extinção, como no PNE anterior. Entretanto, o ensino multisseriado tem sido uma dificuldade recorrente enfrentada pelas escolas do campo, como diferentes estudos têm demonstrado.

Parente (2014) afirma que as escolas multisseriadas em países desenvolvidos e em desenvolvimento evidenciam semelhanças e diferenças expressivas, como: escolas em regiões com redução populacional, com absenteísmo docente elevado ou que adotaram essa organização escolar por opção pedagógica, entre outras. Entretanto, mesmo que o argumento econômico defina a decisão pela multisseriação, o empobrecimento dessas instituições de ensino ocupa maior destaque nos países em desenvolvimento, a exemplo do Brasil.

Em pesquisa realizada por Santos (2013) no Estado de Sergipe, com uma amostra de $21,33 \%$ dos municípios, a multissérie é uma dificuldade enfrentada pelos docentes e silenciada na gestão pública. Na região amazônica e no entorno, a oferta do ensino multisseriado é predominante nas escolas do campo, entretanto, "[...] as classes multisseriadas parecem [...] quase inexistente nas discussões das políticas públicas sobre a prática pedagógica e na formação dos docentes que atuam nesse tipo de ensino" (TERUYA et al., 2013, p. 565).

No Pará, “[...] as escolas multisseriadas atendem $97,45 \%$ da matrícula nas séries iniciais do ensino fundamental no campo" (HAGE, 2006, p. 3). A conclusão desse estudo sinaliza a angústia e solidão de docentes na condução do processo educativo; os gestores justificam a ausência do acompanhamento pedagógico pela falta de estrutura e de pessoal, e os sujeitos do campo se sentem a margem em relação às escolas urbanas.

No Rio Grande do Sul, há relatos sobre o despreparo e a falta de orientação para o trabalho com turmas multisseriadas. Junges (2012) aponta a necessidade de compartilhamento de práticas educativas entre docentes que vivenciam o desafio da multissérie. Ou seja, o cenário educacional para o campo é preocupante em diversos aspectos.

O Brasil ocupa a oitava posição no mundo em número de pessoas adultas sem escolarização (UNESCO, 2014). A PNAD divulgada em 2013 mostrou que os analfabetos perfazem um total de 13,2 milhões de pessoas com 15 anos ou mais (IBGE, 2013). Em 2011, a taxa de analfabetismo adulto nas zonais rurais perfazia um percentual de 21,2\%. Nos últimos anos, essa conjuntura pouco se alterou. Esses estudos evidenciam que o campo necessita de maior atenção para se efetivar o direito à educação e é, pois, nesse sentido, que se esperava do PNE, como política de Estado, uma maior prioridade no estabelecimento de metas e ações para o campo. 
Gráfico 1. Matrícula da Educação Básica no Campo e na Cidade.

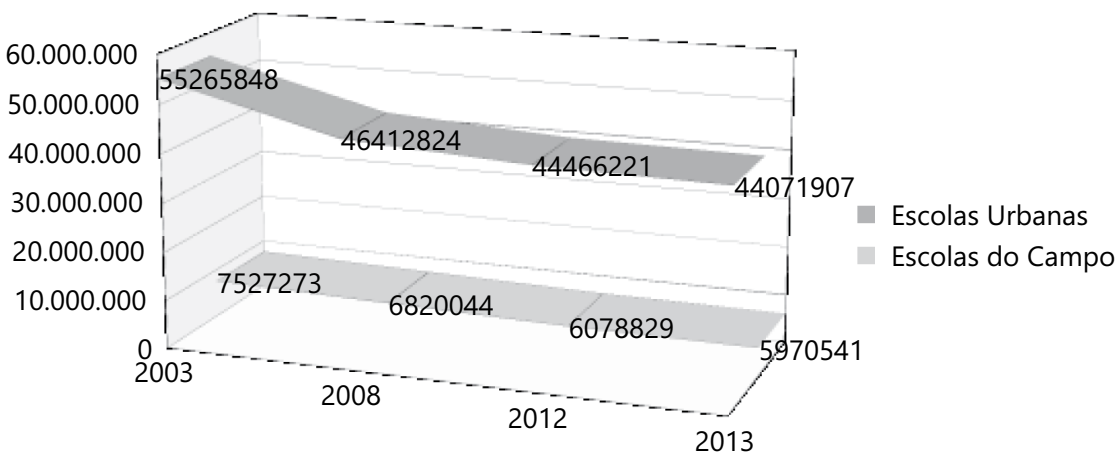

Fonte: Censo Escolar (2013).

Dados do censo escolar demonstram uma redução de $31,4 \%$ das escolas do campo em 10 anos (INEP, 2014).

As preocupações com a diminuição do número de escolas e a acentuada queda de matrículas no campo foi alvo de regulação por parte do Governo Federal, com a criação da Lei n ${ }^{\circ} 12.960 / 2014$ que trata do fechamento dessas escolas. Cabe considerar que a redução de matrículas tem sido ocasionada em decorrência de diversos fatores, a exemplo das mudanças do perfil demográfico brasileiro - redução das taxas de natalidade, nupcialidade e mortalidade (IBGE, 2011).

A necessidade de legislação específica sobre essa questão aponta, para uma realidade de não atendimento ao direito educacional da população campesina, à medida que, quando se fecha a escola da comunidade, muitas crianças ficam sem acesso à educação escolar durante um tempo. Destaca-se, nesse contexto, a situação da educação infantil e do primeiro ano do ensino fundamental, cujas crianças encontram dificuldades, em função da faixa etária com o deslocamento do campo para a sede dos municípios ou para o povoado mais próximo. Nesses casos, não se garante o direito do acesso à escolarização para todos em igualdade de condições.

\section{Considerações finais}

A análise dos planos nacionais de educação evidencia avanços no atual PNE em relação à Educação do Campo, principalmente, na trajetória educacional da população campesina até o momento. Entretanto, há um longo caminho a ser percorrido, como evidenciam os dados apresentados, antes que se possa afirmar que o Brasil garante o direito educacional aos cidadãos do campo. 
Quando agrupamos as dezessete estratégias do atual PNE que versam sobre Educação do Campo, não é possível visualizar concretamente ação efetiva para a melhoria dessa modalidade de educação. A falta de objetividade na redação do texto das estratégias, ao imprimir caráter genérico, torna difícil a identificação do que tais estratégias representam em termos de ação política do Estado para elevar a qualidade da educação brasileira para a população campesina.

A inexistência de metas específicas para a Educação do Campo demonstra seu desfavorecimento em relação à urbana. $\mathrm{O}$ contexto dessas estratégias sem previsão de execução é motivo de preocupação no que diz respeito a sua viabilização, tendo em vista que as mesmas podem ser mantidas apenas em caráter documental, o que, inclusive, pode-se replicar nos Planos Municipais de Educação aprovados.

A estratégia, prevista no PNE, de garantia do transporte escolar também é motivo de preocupação acerca da "sobrevivência" das escolas do campo. Além disso, ao estimular a saída do campo de crianças, adolescentes e jovens aprendizes, leva ao desconhecimento dos que vivem no campo de sua própria realidade.

As escolas multisseriadas que têm se multiplicado no cenário campesino e funcionam, na maioria das unidades, como simples junção de anos escolares no mesmo espaço, não poderia continuar invisibilizada no PNE. Dados do censo escolar de 2016 apontam a unidocência em 7,2\% das escolas brasileiras todas relacionadas ao meio rural (INEP, 2017). Isso demonstra que a multissérie continua sendo um desafio. Compreende-se que o não enfrentamento desse cenário, tão representativo da realidade da educação do campo, pode comprometer a garantia do direito educacional e da qualidade da educação.

À medida que o contexto camponês, como objeto de estudo na escola, não constitui preocupação das escolas urbanas, tampouco nas escolas nucleadas, produz-se para esses sujeitos a invisibilidade do campo como local de vida. Nessas escolas, não são consideradas as especificidades da Educação do Campo na política curricular, na organização do processo educativo escolar, na relação com o tempo e com os espaços do campo.

Tendo como referência a análise empreendida nesse texto, destaca-se a distância ainda existente de consolidação de uma Educação do Campo nos moldes reivindicados pelos movimentos sociais e sindicais do campo. Conclui-se, portanto, que a proposta de educação defendida por esses movimentos, que congregou força política no final da década de 1990 e na primeira década do século XXI, entra na segunda década deste século no ostracismo, em termos de ações concretas do Estado. 


\title{
Countryside education in the National Education Plan: tensions between guaranteeing and denying the right to education
}

\begin{abstract}
This bibliographic article discusses the right to education for rural populations and analyzes the guarantee of this right in the documents that guide education policy in the country in recent decades. The empirical material analyzed is composed by the Decennial Education Plan (1993) and the Nationals Education Plan (2001 and 2014). The analysis focused in reflecting on the way rural education discussion is presented in the documents analyzed, explaining the tensions emerging from the current plan, which oscillates between the warranty and the non-fulfilment of the right to education. Furthermore, this article problematizes the conception of Rural Education and assumes the perspective of countryside education in the reflection of legal texts. The conclusions indicate advances in the National Education Plan (2014) in relation to previous plans, not presenting, however, significant achievements regarding countryside education. There is thus a long way to go before it can be said that Brazil ensures educational rights for the peasant population.
\end{abstract}

Keywords: Countryside education. National Education Plan. Public policy.

\section{La Educación del Campo en el Plan Nacional de Educación: tensiones entre la garantía y la negación del derecho a la educación.}

\section{Resumen}

El artículo, de tipo bibliográfico, discute el derecho a la educación para las poblaciones rurales y analiza la garantía de este derecho en los documentos que guían la política de educación en el país en las últimas décadas. El material empírico analizado está compuesto por el Plan Decenal de Educación (1993) y los Planes Nacionales de Educación (2001 y 2014). El análisis se centra en reflexionar sobre el modo de comparecencia del debate de la educación del campo en los documentos analizados, explicitando las tensiones que emergen del Plan vigente, que oscila entre la garantía y la no efectividad del derecho a la educación. Además, aborda el planteamiento de Educación Rural y asume la perspectiva de la Educación del campo en la reflexión de los textos legales. Los resultados indican avances en el Plan Nacional de Educación (2014) en relación con los planes anteriores, no presentando, sin embargo, importantes logros en cuanto a la Educación del Campo. Así, existe un largo camino por recorrer antes de que pueda decirse si Brasil asegura los derechos a la educación para la población campesina.

Palabras claves: Educación del campo. Plan de Educación Nacional. Política pública. 


\section{Referências}

AGLIARDI, D. A.; WELTER, C. B.; PIEROSAN, M. R. O novo Plano Nacional Decenal de Educação e as políticas educacionais de estado: velhas metas novos desafios. In: SEMINÁRIO DE PESQUISA EM EDUCAÇÃO DA REGIÃO SUL - ANPED SUL, 9., 2012, Caxias do Sul. Anais... Caxias do Sul: Universidade de Caxias do Sul, 2012. p. 1-18

AGUIAR, M. A. da S. Avaliação do Plano Nacional de Educação 2001-2009: questões para reflexão. Educação \& Sociedade, Campinas, v. 31, n. 112, p. 707-727, jul./set. 2010.

ANDRADE, M. R.; DI PIERRO, M. C. A construção de uma política de educação na reforma agrária. In: ANDRADE, M. R. et al. (Org.). A educação na reforma agrária em perspectiva: uma avaliação do programa nacional de educação na reforma agrária. São Paulo: Ação Educativa; Brasília, DF: PRONERA, 2004. p. 19-35.

BARREIRO, I. M. de F. Articulação entre desenvolvimento econômico e educação aos países latinos: educação rural no Brasil - anos cinquenta. Projeto História: Revista do Programa de Estudos Pós-Graduados de História, São Paulo, v. 32, p. 123-142, jun. 2006.

. Estrutura e funcionamento da campanha nacional de educação rural.

In: . Política de educação no campo: para além da alfabetização (1952-1963) [online]. São Paulo: Editora UNESP; Cultura Acadêmica, 2010. p. $49-72$.

BARREIRO, I. M. de F. Formação para o ensino agrícola nos Centros de Treinamento de Professores e de Auxiliares Rurais (1952-1963). Revista Brasileira de Educação, Rio de Janeiro, v. 18, n. 54, jul./set. 2013.

BRASIL. Plano Decenal de Educação para Todos. Ministério da Educação e do Desporto. Brasília, DF, 1993.

. Lei $\mathrm{n}^{\circ} 9.394$, de 20 de dezembro de 1996. Estabelece as diretrizes e bases da educação nacional. Diário Oficial da República Federativa do Brasil, Brasília, DF, 23 dez. 1996.

. Secretaria de Educação Fundamental. Parâmetros Curriculares Nacionais. Brasília: MEC, 1997. 
BRASIL. Lei ${ }^{\circ}$ 10.172, de 09 de janeiro de 2001. Aprova o Plano Nacional de Educação e dá outras providências. Diário Oficial da União da República Federativa do Brasil, Brasília, DF, 10 jan. 2001 Disponível em: <http://www. planalto.gov.br/ccivil_03/leis/leis_2001/110172.htm>. Acesso em: 29 nov. 2017.

. Lei ${ }^{\circ} 6.253$, de 13 de novembro de 2007. Dispõe sobre o Fundo de Manutenção e Desenvolvimento da Educação Básica e de Valorização dos Profissionais da Educação. Diário Oficial da União, Brasília, DF, 26 jun. 2007. Disponível em: <http://www.planalto.gov.br/ccivil_03/_ato20072010/2007/decreto/d6253.htm>. Disponível em: 29 nov. 2017.

. Lei ${ }^{\circ} 12.960$, de 27 de março de 2014a. Altera a Lei n. ${ }^{\circ} 9.394$, de 20 de dezembro de 1996. Dispõe sobre o fechamento de escolas do campo, indígenas e quilombolas. Diário Oficial da União, Brasília, DF, 26 mar. 2014a. Retificado em DOU, 31 mar. 2014. Disponível em: <http://www.planalto.gov. br/ccivil_03/_ato2011-2014/2014/lei/112960.htm>. Acesso em: 29 nov. 2017

. Lei $\mathrm{n}^{\mathrm{o}} 13.005$, de 25 de junho de 2014b. Aprova o Plano Nacional de Educação - PNE e dá outras providências. Diário Oficial da União da República Federativa do Brasil, Brasília, DF, 26 jun. 2014b. Disponível em: $<$ http://www.planalto.gov.br/CCIVIL_03/_Ato2011-2014/2014/Lei/L13005. htm>. Acesso em: 29 nov. 2017.

CALAZANS, M. J. C. Para compreender a educação do estado no meio rural: traços de uma trajetória. In: THERRIEN, J.; DAMASCENO, M. N. Educação e escola no campo. Papirus, Campinas, 1993. p. 15-51.

CALDART, R. S. A escola do campo em movimento. Currículo sem Fronteiras, v. 3, n. 1, p. 60-81, jan./jun. 2003.

CANCIAN, N. Brasil fecha, em média, oito escolas por dia na região rural. Folha de S. Paulo, São Paulo, 3 mar. 2014. Disponível em: http://www1.folha. uol.com.br/educacao/2014/03/1420332-pais-fecha-oito-escolas-por-dia-nazona-rural.shtml. Acesso em: 29 nov. 2017.

DIAS SOBRINHO, J. Democratização, qualidade e crise da educação superior: faces da exclusão e limites da inclusão. Educação \& Sociedade, Campinas, v. 31, n. 113, p. 1223-1245, out./dez. 2010.

FERNANDES, F. Mudanças sociais no Brasil aspectos do desenvolvimento da sociedade brasileira. 1. ed. digital. São Paulo: Editora Globo, 2013.

GOHN, M. da G. M. Lutas e movimentos pela educação no Brasil a partir de 1970. EccoS-Revista Científica, São Paulo, v. 11, n. 1, p. 23-38, jan.jun. 2009. 
GRITTI, S. M. Técnico em agropecuária: servir à agricultura familiar ou ser desempregado da agricultura capitalista. 2007. 252 f. Tese (Doutorado em Educação), Universidade Federal do Rio Grande do Sul, Porto Alegre, 2007.

HADDAD, S. (Org.). Banco Mundial, OCMC e FMI: o impacto nas políticas educacionais. São Paulo: Cortez, 2008.

HAGE, S. M. A realidade das escolas multisseriadas frente às conquistas na legislação educacional. In: REUNIÃO DA ANPED, 29., 2006, Caxambu, MG. Anais... Caxambu: ANPED, 2006. Disponível em: <http://29reuniao.anped. org.br/?_ga=2.91290777.22778423.1512060597-984301338.1511790999>. Acesso em: 09 mar. 2016.

INSTITUTO BRASILEIRO DE GEOGRAFIA E ESTATÍSTICA - IBGE. Características da população e dos domicílios: resultados do universo. Rio de Janeiro: IBGE, 2011.

2013.

. Pesquisa nacional por amostra de domicílios. Brasília, DF: IBGE,

INSTITUTO NACIONAL DE ESTUDOS E PESQUISAS EDUCACIONAIS ANÍSIO TEIXEIRA - INEP. Pesquisa nacional da educação na reforma agrária. Brasília, DF: INEP, Ministério da Educação, 2004.

. Censo Escolar da Educação Básica 2013: resumo técnico. Brasília, DF: INEP, 2014.

. Censo Escolar da Educação Básica 2016: notas estatísticas. Brasília, DF: INEP, 2017.

JUNGES, D. L. V. Classe multisseriada e formação docente: relatos de uma professora do campo. ANPED SUL, 9., 2012, Caxias do Sul, RS, 2012. Anais... Caxias do Sul, RS: ANPED, 2012. Disponível em: <http://www.ucs. br/etc/conferencias/index.php/anpedsul/9anpedsul/paper/viewFile/481/435>. Acesso: 09 mar. 2016.

KOLLING, E. J.; NERY, I.; MOLINA, M. C. (Org.). Por uma educação básica do campo. Brasília, DF: UnB, 1999.

LOUREIRO, K. Neoliberalismo e questão agrária: as consequências para o campo brasileiro. [S. 1.]: [s. n.], 2003. Disponível em: < http://www.angelfire. com/planet/anpuhes/klitia4.htm >. Acesso em: 02 mar. 2016. 
MINISTÉRIO DA EDUCAÇÃO - MEC. 2013. Disponível em: <http://portal. inep.gov.br/documentos-e-legislacao13>. Acesso em: 16 abr. 2016.

MOLINA, M. C. Taxa de analfabetismo no campo é três vezes maior do que a das áreas urbanas. In: Rede Comunitária. 2011. Disponível em: $<$ http://redeccom. blogspot.com.br/2011/05/blog-post_06.html>. Acesso em: 02 mar. 2016.

MOVIMENTO DOS TRABALHADORES RURAIS SEM TERRA - MST. Disponível em: <http://www.mst.org.br>. Acesso em: 15 mar. 2016.

OLIVEIRA, A. U. A longa marcha do campesinato brasileiro: movimentos sociais, conflitos e reforma agrária. Estudos Avançados, São Paulo, v. 15, n. 43, p. 185-206, set./dez. 2001.

. Modo de produção capitalista, agricultura e reforma agrária. São Paulo: Labur Edições, 2007.

ORGANIZAÇÃO DAS NAÇÕES UNIDAS PARA A EDUCAÇÃO, A CIÊNCIA E A CULTURA - UNESCO. Ensinar e aprender: alcançar a qualidade para todos, relatório conciso. Paris: Unesco, 2014.

PARENTE, C. da M. D. Escolas multisseriadas: a experiência internacional e reflexões para o caso brasileiro. Ensaio: Avaliação e Políticas Públicas em Educação. Rio de Janeiro, v. 22, n. 82, p. 57-88, mar. 2014.

PNE em movimento. Disponível em: $<$ http://pne.mec.gov.br/>. Acesso em: 10 out. 2015.

PRADO, A. A. Ruralismo pedagógico no Brasil do Estado Novo. Estudos Sociedade e Agricultura. Rio de Janeiro, n. 4, p. 5-27, jul. 1995.

REFORMA AGRÁRIA EM DADOS. Manifesto das educadoras e dos educadores da reforma agrária ao povo brasileiro. Brasília, DF: MST, 1997. Disponível em: $<\mathrm{http}$ ://www.reformaagrariaemdados.org.br $>$. Acesso em: 08 mar. 2016.

RIBEIRO, M. Movimento camponês, trabalho e educação - liberdade, autonomia, emancipação: princípios/fins da formação humana. São Paulo: Expressão Popular, 2010.

. Educação rural. In: CALDART, R. S. et al. (Org.). Dicionário da educação do campo. Rio de Janeiro, São Paulo: Expressão Popular, 2012. 
RIOS, J. A. V. P. De lavradora a professora primária na roça: narrativas, docência e profissionalização. Revista Brasileira de Educação, Rio de Janeiro, v. 21, n. 65, p. 325-346, abr./jun. 2016.

SANTOS, M. Educação do campo uma política em construção: desafios para Sergipe e para o Brasil. 2013. 302 f. Tese (Doutorado em Educação), Universidade Federal de Sergipe, São Cristóvão, 2013.

SILVA, M. A. da. Qualidade social da educação pública: algumas aproximações. Caderno CEDES, Campinas, v. 29, n. 78, p. 216-226, maio/ ago. 2009.

SINGER, P. Poder, política e educação. Revista Brasileira de Educação, Rio de Janeiro, n. 1, p. 5-15, jan./abr. 1996. Disponível em: <http://www. ia.ufrrj.br/ppgea/conteudo/T2-1SF/Sandra/Poder,\%20pol\%EDtica $\% 20 \mathrm{e} \% 20$ educa\%E7\%E3o.pdf $>$. Acesso em: 10 mar. 2016.

SOUZA, D. B. de. Avaliações Finais sobre o PNE 2001-2010 e Preliminares do PNE 2014-2024. Estudos em Avaliação Educacional, São Paulo, v. 25, n. 59, p. 140-170, set./dez. 2014.

TERUYA, T. K et al. Classes multisseriadas no Acre. Revista Brasileira Estudos Pedagógicos, Brasília, v. 94, n. 237, p. 564-584, 2013.

VALENTE, I. Plano Nacional de Educação. Rio de Janeiro: DP\&A, 2001.

VIEIRA, M. L. et al. O processo de nucleação das escolas do campo no município de Poço Redondo/SE. In: COLÓQUIO INTERNACIONAL: Educação e Contemporaneidade, 6., 2012, São Cristóvão. Anais... São Cristóvão, 2012.

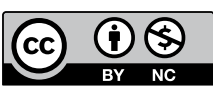

\section{Informações da autora}

Marilene Santos: Doutora em Educação. Professora Adjunta do Departamento de Educação da Universidade Federal de Sergipe. Grupo de pesquisa: Educação e Movimentos Sociais - GPEMS, Grupo de Estudos e Pesquisas Identidades e Alteridades - GEPIADDE. Membro da Associação Brasileira de Pesquisadoras e Pesquisadores pela Justiça Social -ABRAPPS. Contato: mari.santos@uol.com.br 